\title{
Relationship Between Yearly Fluctuations in Fusarium Head Blight Intensity and Environmental Variables: A Window-Pane Analysis
}

\author{
A. B. Kriss, P. A. Paul, and L. V. Madden
}

Department of Plant Pathology, The Ohio State University, Ohio Agricultural Research and Development Center, Wooster 44691. Accepted for publication 12 April 2010.

\begin{abstract}
Kriss, A. B., Paul, P. A., and Madden, L. V. 2010. Relationship between yearly fluctuations in Fusarium head blight intensity and environmental variables: A window-pane analysis. Phytopathology 100:784-797.

Window-pane methodology was used to determine the length and starting time of temporal windows where environmental variables were associated with annual fluctuations of Fusarium head blight (FHB) intensity in wheat. Initial analysis involved FHB intensity observations for Ohio (44 years), with additional analyses for Indiana (36 years), Kansas (28 years), and North Dakota (23 years). Selected window lengths of 10 to 280 days were evaluated, with starting times from approximate crop maturity back to the approximate time of planting. Associations were quantified with Spearman rank correlation coefficients. Significance for a given variable (for any window starting time in a collection of

total daily precipitation) were found to be positively correlated with FHB intensity for multiple window lengths and starting times; however, the highest correlations were primarily for shorter-length windows (especially 15 and 30 days) at similar starting times during the final 60 days of the growing season, particularly near the time of anthesis. This period encompasses spore production, dispersal, and fungal colonization of wheat spikes. There was no evidence of significant correlations between FHB and temperature-only variables for any time window; however, variables that combined aspects of moisture or wetness with temperature (e.g., duration of temperature between 15 and $30^{\circ} \mathrm{C}$ and $\mathrm{RH} \geq 80 \%$ ) were positively correlated with FHB intensity. Results confirm that the intensity of FHB in a region depends, at least in part, on environmental conditions during relatively short, critical time periods for epidemic development.
\end{abstract} starting times) was declared using the Simes' multiplicity adjustment; at individual time windows, significant correlations were declared when the individual (unadjusted) $P$ values were $<0.005$. In all states, moisture- or wetness-related variables (e.g., daily average relative humidity $[\mathrm{RH}]$ and
Additional keywords: disease forecasting, Fusarium graminearum, Gibberella zeae, multiple testing, wheat scab.

and macroconidia are transported to the wheat spike by wind (22) or water splash (37), and density of spores on wheat spikes (reflecting both dispersal and spore production on debris) has been associated with high relative humidity, high rain intensity, and moderate temperatures in empirical studies (38). Infection of wheat flowers occurs at and shortly after anthesis, and relative humidity has been associated with increased disease intensity $(1,3,4,45)$. Colonization of the wheat spike and production of DON have been related to atmospheric moisture $(14,15,19,49)$ but there is still uncertainty regarding the effect of moisture and rainfall on DON. There is a considerable degree of heterogeneity found for all reported relationships $(14,15)$.

Various models have been developed for FHB prediction, usually based on empirical analyses of observations of disease and meteorological conditions $(16,19,29,31,33,42,44)$, although some models are of the systems type, based on submodels for environmental effects on disease-cycle components $(18,35,44)$. The current national FHB forecaster (for 24 U.S. states) is based on empirical logistic regression models, and uses local weather conditions for the week before anthesis (Feekes growth stage 10.5.1) to predict risk of major FHB epidemics so that management decisions (e.g., application of a fungicide) can be made in a timely manner (17-19). It is assumed that the forecaster is identifying periods favorable for spore production immediately before anthesis (17). Less researched is whether the annual variability in FHB disease level and yield loss in a region can be related to variability from year to year in environmental conditions over short or long time scales during different periods of the growing season. Historical records of FHB intensity (broadly defined) over multiple decades in Ohio and three other U.S. states provide data sets that can be used to address this issue. 
To investigate possible correlations between environmental variables and annual variations in FHB intensity, we used an empirical method that was first formalized by Coakley and colleagues in 1982 (11), now commonly called "window-pane" analysis. This methodology - a form of data mining-has since been expanded in different ways for use with wheat $(12,13$, 41,58 ), potato (23), rice (8), and banana (10) diseases. This analysis can be used to determine the length (duration) and starting (or ending) time of the temporal windows where environmental variables are significantly associated with disease intensity.

The objectives of this research were to (i) determine environmental variables most associated with annual fluctuations of FHB intensity in wheat in Ohio; (ii) determine time-window lengths and starting or ending times when FHB intensity was most highly correlated with environmental variables; and (iii) compare correlation results found for Ohio with those found for three other states: Indiana, Kansas, and North Dakota. Because the window-pane methodology involves the calculation of a large number of correlated test results, approaches to adjust for the multiple-testing problem were explored and utilized in the investigation.

\section{MATERIALS AND METHODS}

Disease data. In Ohio, FHB intensity in the state (broadly defined to include estimated yield impact) was rated on an ordinal scale of 0 to 9 at the end of each wheat season for 44 years (1964 to 2008). In each year, FHB intensity was assigned the rating score relative to the score assigned the previous years, based on observed disease levels and yield losses in cultivar trials and reports coming in from across the state. In addition to FHB, other diseases and yield-impacting (biotic and abiotic) stresses were also rated on the 0 to 9 scale; therefore, for any given year, the magnitude of one problem was determined relative to the occurrence of other (potential) problems evaluated in that same year. The rating was made by either a wheat breeder or field-crop pathologist in Wooster, OH. A year such as 1996, with widespread FHB outbreaks and resulting yield losses (>40\%) (30), serves as a reference standard when assigning FHB scores.

In Indiana, disease was assessed for 36 years (1973 to 2008) in cultivar nurseries by Purdue University researchers. Observations used here were obtained from the susceptible "check" cultivars. For all years, FHB disease index (field severity) was estimated as the mean percentage of spike area with symptoms (including the spikes with no symptoms). In Kansas, mean disease index was assessed for 28 years (1978, 1980, and 1982 to 2007) by Kansas State University, Kansas Department of Agriculture, and United States Department of Agriculture-Agricultural Research Service personnel, based on surveys of wheat in the state. No assessment was made in 1979 and 1981. So-called "trace" amounts of FHB were recorded for some of the years; we assigned these an index value of 0.001 . In North Dakota, the impact of FHB was rated at the end of each season for 23 years (1986 to 2008) based on results from field surveys for yield losses by North Dakota State University extension agents and specialists. Estimated yield losses for the disease were expressed on an ordinal scale of 0 to 9 , where $0=$ no visible evidence of the disease and $9=$ the highest estimated yield loss observed in the state ( 2.4 million metric tons) over the years of observations. Although the ordinal scale used in both Ohio and North Dakota ranged from 0 to 9, the individual values do not necessarily have equivalent meaning in each location. However, for the chosen statistical analysis (see below), only the order of the values within a location matter in the interpretation of analytical results.

Meteorological data. For Ohio, weather data were gathered from weather stations near Wooster by the National Climatic Data Center (NCDC) and the Ohio Agricultural Research and Development Center. Daily maximum and minimum temperature and total precipitation were available for all years. Daily average temperature was calculated as half the sum of the maximum and minimum in 1964 to 1982 , and as the arithmetic mean of hourly data thereafter. Maximum, minimum, and average relative humidity were available in 1982 to 2008 . A nearby weather station (WBAN 14895) provided 3-h relative humidity data in 1964 to 1981, which was used to find the daily maximum, minimum, and average relative humidity. This weather station was also used for missing data (total of 22 days) in Wooster for all other years. Average daily dew point was calculated from the average temperature and relative humidity (63) (when dew point measurements were not directly available). In general, atmospheric moisture for hourly data was provided as dew point temperature (in combination with ambient air temperature); relative humidity was then determined using a standard formula based on air temperature and dew point (National Oceanic and Atmospheric Administration, 2009, NCDC). Based partly on previously published results for FHB and other diseases, several combinations of the weather variables were investigated in the construction of environmental variables for different time windows (Table 1), as described below.

For the other states, weather data were gathered from weather stations near Lafayette, IN, Manhattan, KS, and Fargo, ND, by the NCDC and the Indiana State Climate Office, the Kansas State University Research and Extension Weather Data Library, and the North Dakota Agricultural Weather Network, respectively. As with Ohio, relative humidity was calculated from air temperature and dew point depression (when relative humidity was not provided). All data missing from Lafayette, IN, and Manhattan, KS were collected from nearby weather stations (WBAN 93819 and WBAN 13996).

TABLE 1. Window lengths (Length) (days) and calendar dates for winter and spring wheat locations used in window-pane analysis of Fusarium head blight

\begin{tabular}{|c|c|c|c|c|}
\hline \multirow[b]{2}{*}{ Length } & \multicolumn{2}{|r|}{ Winter wheat ${ }^{\mathrm{a}}$} & \multicolumn{2}{|r|}{ Spring wheat ${ }^{\mathrm{b}}$} \\
\hline & No. of windows & Start date (end date: 24 September) & No. of windows & Start date (end date: 18 January) \\
\hline 10 & 270 & 30 June, 29 June, ..., 4 October, 3 October & 200 & 15 August, 14 August, ..., 28 January, 27 January \\
\hline 15 & 265 & 30 June, 29 June, ..., 9 October, 8 October & 195 & 15 August, 14 August, ..., 2 February, 1 February \\
\hline 30 & 250 & 30 June, 29 June, ..., 24 October, 23 October & 180 & 15 August, 14 August, ..., 17 February, 16 February \\
\hline 60 & 220 & 30 June, 29 June, ..., 23 November, 22 November & 150 & 15 August, 14 August, ..., 19 Mar, 18 Mar \\
\hline 90 & 190 & 30 June, 29 June, ..., 23 December, 22 December & 120 & 15 August, 14 August, ..., 18 Apr, 17 Apr \\
\hline 120 & 160 & 30 June, 29 June, ..., 22 January, 21 January & 90 & 15 August, 14 August, ..., 18 May, 17 May \\
\hline 150 & 130 & 30 June, 29 June, ..., 21 February, 20 February & 60 & 15 August, 14 August, ..., 17 June, 16 June \\
\hline 180 & 100 & 30 June, 29 June, ..., 23 Mar, 22 Mar & 30 & 15 August, 14 August, ..., 17 July, 16 July \\
\hline 210 & 70 & 30 June, 29 June, ..., 22 Apr, 21 Apr & 1 & 15 August \\
\hline 240 & 40 & 30 June, 29 June, ..., 22 May, 21 May & $\ldots$ & $\ldots$ \\
\hline 280 & 1 & 30 June & $\ldots$ & $\ldots$ \\
\hline
\end{tabular}

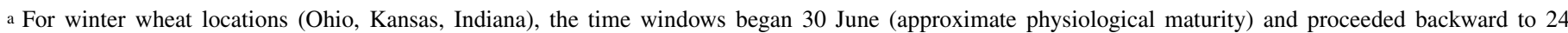
September of the previous year (approximate time of planting).

b For spring wheat (North Dakota), the time windows began 15 August (approximate physiological maturity) and proceeded backward to 18 January. 
Window-pane analysis-variable construction. The concept underlying window-pane analysis is the specification of a time window of defined length or duration and the construction of summary environmental variables (e.g., means) for the specified window. This time window (e.g., 30 days) is moved (or slid) along the total time frame of interest (e.g., a year or a growing season) in daily increments, so that the environmental data from the entire time frame is ultimately considered in the data analysis. With a defined starting time and window length, the ending time of the window is automatically determined. Time windows of environmental data were constructed separately for each year. The "beginning" of the time frame in the analysis for Ohio data was considered the approximate time of wheat maturity (30 June; for convenience of expression, given as time " 0 "), and the windows proceeded backward over this time frame in daily increments to end at the approximate time of planting (24 September; time "-280").

Summary environmental variables were calculated for a wide range of time-window lengths and starting times of the windows for each year. The fixed-time windows had lengths of 10, 15, 30, $60,90,120,150,180,210,240$, and 280 days (Table 1). As an example, the first window of length 10 began on 30 June (time 0 ) and ended on 21 June, the second 10-day window began on 29 June (time -1) and ended on 20 June, and the final 10-day window began on 3 October (time -270) and ended on 24 September. Two successive time windows (of the same length) share all but one day of data. There were, in total, 270 windows of length 10 for each year, with smaller numbers of windows of longer lengths (Table 1). The construction of summary variables for the different window lengths and starting times was done with the 2007 version of Microsoft Excel.

The above-described window lengths for Ohio were also used for Indiana, Kansas, and North Dakota. The same starting time was used for the windows for Indiana and Kansas. However, to correspond to the spring wheat-growing season in North Dakota, a starting time of 15 August (time 0) was used; time windows ended in mid-January (time -210) for this state. Although, for spring wheat, the growing season starts in approximately late April or early May of the same year (time $\approx-105$ ), we still continued time windows back further in time to capture periods when overwintering is occurring. For all states, the time frame was linked to the calendar dates and not to specific crop growth stages. This is because there can be a range of dates for a particular growth stage in any given area, and because cultivars vary in maturity and, consequently, the time of occurrence of any specific growth stage. In addition, records were not kept in the historical data for the times of specific stages in several of the years. We do refer to the growth stages that typically occur during approximate time periods in a given location, based on historical norms and experiences of the local experts.
For each window length and start time, several summary environmental variables were calculated (Table 2), based on either averages or summations of temperature (e.g., average daily temperature $[\mathrm{AT}]$ ), relative humidity (e.g., average daily relative humidity $[\mathrm{ARH}]$ ), negative dew point depression, precipitation, or combinations of these. Some variables were based on the summation of times (days or hours) where certain conditions were met (e.g., T1530). Most variables were based on the recorded daily meteorological conditions (or from the daily average or summations when hourly or every 3-h data were available); however, HRH90, THRH90, HRH80, and THRH80 were based strictly on hourly values. Construction of the summary variables was based, in part, on the variables used in other studies $(31,38)$. The environmental variables for the longer time windows generally represent climatic conditions and can be used to relate overall climate to FHB epidemics. In contrast, the environmental variables for the shortest time windows, which are more weatherlike summaries of the environment, could be used to associate environment with particular components of the disease cycle (e.g., spore production, infection, spike colonization, and so on).

Window-pane analysis-statistics. The relationship between each summary environmental variable and disease intensity was quantified with an estimated Spearman rank correlation coefficient $(r)$ (55) for each of the window lengths and starting times. This rank-based nonparametric correlation was used due to the ordinal nature of the FHB intensity data in Ohio and North Dakota, and because of the non-normal data in the other locations. The Spearman correlation coefficient determines the degree to which a monotonic relationship exists between a pair of variables (52); with this type of correlation, only the order of the variables matters, not the actual values.

The summary environmental variables were exported to SAS (SAS, Inc., Cary, NC) for analysis. The CORR procedure was then used to estimate the Spearman correlation coefficient and significance level $(P)$ across all years, based on a one-sided test for each variable at each of the time-window lengths and starting or ending times. That is, the correlation was based on $N=44,36$, 28, and 23 observations for Ohio, Indiana, Kansas, and North Dakota, respectively. For instance, with the Ohio data set, there were 44 values of the environmental variable HRH90 with window starting time of 0 and a length of 10 days; the correlation of these environmental observations and the yearly FHB intensity values was estimated with the CORR procedure. Then, the correlation was estimated between FHB intensity and the 44 HRH90 values with a window starting time of -1 and window length of 10 days. In the same fashion, the correlations were estimated for all the window starting times and window lengths for HRH90 and then for all the other environmental variables (and then for all the other locations). One-sided tests were performed because we

TABLE 2. Description of environmental variables, with units in parentheses, used in window-pane analysis of Fusarium head blight

\begin{tabular}{|c|c|}
\hline Weather variables & Description \\
\hline AT & Average mean daily temperature $\left({ }^{\circ} \mathrm{C}\right)$ \\
\hline $\mathrm{T} 1530$ & Number of days with average mean daily temperature between 15 and $30^{\circ} \mathrm{C}$ \\
\hline DD15 & Total degree days (base 15 ) over window length $\left({ }^{\circ} \mathrm{C}\right)$ \\
\hline DD9 & Total degree days (base 9) over window length $\left({ }^{\circ} \mathrm{C}\right)$ \\
\hline NDD15 & Total negative degree-days (base 15 ) over window length $\left({ }^{\circ} \mathrm{C}\right)$ \\
\hline NDD9 & Total negative degree-days (base 9) over window length $\left({ }^{\circ} \mathrm{C}\right)$ \\
\hline $\mathrm{AD}$ & Average mean daily dew point $\left({ }^{\circ} \mathrm{C}\right)$ \\
\hline $\mathrm{ARH}$ & Average mean daily relative humidity $(\%)$ \\
\hline MRH & Average maximum daily relative humidity $(\%)$ \\
\hline NDPD & Average mean negative dew point depression $\left({ }^{\circ} \mathrm{C}\right)$ \\
\hline $\mathrm{TP}$ & Total precipitation over window length (mm) \\
\hline IP & Number of days with precipitation over window length \\
\hline $\mathrm{T} 1530 \mathrm{P}$ & Number of days with average mean daily temperature between 15 and $30^{\circ} \mathrm{C}$ and precipitation over window length \\
\hline HRH90 & Number of hours with relative humidity $>90 \%$ \\
\hline THRH90 & Number of hours with temperature between 15 and $30^{\circ} \mathrm{C}$ and relative humidity $>90 \%$ \\
\hline HRH80 & Number of hours with relative humidity $>80 \%$ \\
\hline THRH80 & Number of hours with temperature between 15 and $30^{\circ} \mathrm{C}$ and relative humidity $>80 \%$ \\
\hline
\end{tabular}


hypothesized that the effect of an environmental variable would be manifested in only a single direction. Windows (for a given length) with nonzero association between disease intensity and an environmental variable were identified with the magnitude of the individual $P$ value for the different starting times of the windows. When one is dealing only with a single test result, in general, a positive correlation is declared if $P \leq \alpha$, where $\alpha$ is the prespecified significance level for an individual test. For windowpane analysis, multiple correlated test statistics are obtained, which require adjustments to the simple hypothesis-testing problem.

Window-pane analysis-multiple hypothesis testing. This analysis involves a large number of test statistics; for instance, with the 10-day window length, there are 270 windows (and, hence, 270 correlations) for the 280 -day time frame. Because of the multiple testing of correlations, the global (experiment-wise, family-wise) significance level $\left(P_{g}\right)$-for an effect "somewhere" across all the windows-will be higher than the critical significance level $(\alpha)$ set for the individual-test decisions (60). As a consequence, there can be too many "false positives" (i.e., falsely declaring correlations to be $>0$ ) across the collection of test results. Additionally, the calculated statistics are correlated with each other with this type of analysis, because they involve the same disease data, because adjacent and nearby time windows share multiple days of the same environmental data, and because large-scale climatic patterns will affect weather data over successive days. These correlations of the test statistics complicate the methodology for multiplicity adjustments compared with when there are collections of independent tests, and there is no clear-cut best approach to use for the adjustment (60). However, the degree of the adjustment for multiplicity is much less for correlated tests results than for independent tests (43). The problem with all multiple-testing adjustments is the low or very low statistical power of the test results (i.e., in order to control the probability of a false positive, the probability of correctly detecting a true positive result can become very small) (60). Some authors even argue against adjustments when the primary interest is in the individual test results, such as whether or not a particular correlation is $>0$ $(46,48)$. This issue has not been formally addressed in previous uses of window-pane analysis $(41,58)$.

We dealt with the multiple-testing problem in three separate ways. First, for each environmental variable and window length, we performed a global test of significance across all window starting times using the Simes' method (53). This is a test for the global null hypothesis $\left(H_{0(g)}\right)$ that none of the individual correlations are significant, and the alternative $\left(H_{a(g)}\right)$ that at least one is $>0$. The Simes' method is based on the ordering of individual $P$ values $\left(P_{j}\right)$ from low to high in a collection of $k$ (possibly) correlated test results, where $j$ represents the $j$ th smallest individual $P$ value $(j=1, \ldots, k)$. If $\alpha_{g}$ is the prespecified global significance level for the collection of tests $\left(\alpha_{g}=0.05\right.$ in our study), $H_{0(g)}$ is rejected if $P_{j} \leq j \alpha_{g} / k$ for any of the $j$ tests. Based on the number of tests and the order of the achieved significance levels, an adjusted individual $P_{j}$ value can also be obtained $\left(\widetilde{P}_{j}\right)$ as explained in Westfall et al. (60); the global $P$ value $\left(P_{g}\right)$ is the minimum of the $\widetilde{P}_{j}$ values. Values of $P_{g}<\alpha_{g}(0.05)$ are considered significant for the global test. With the Simes' method, no decision is made on the significance of the individual test results (i.e., estimated correlation coefficients here); therefore, a significant result in our case $\left(P_{j} \leq j \alpha_{g} / k\right.$ for any $\left.j\right)$ only means that one or more of the correlations is $>0$.

Second, the individual estimated correlation coefficients were compared with critical values corresponding to individual prespecified significance levels ( $\alpha$ values) of 0.005 instead of 0.05 . That is, the $j$ th individual correlation was considered to be $>0$ if $P_{j} \leq 0.005$. Use of $\alpha=0.005$ makes it harder to declare that a correlation exceeded 0 , which provided some protection from excessive numbers of false positives for the individual correlation results. As with all multiple-testing adjustments, however, the correction does lead to an increased number of false negatives (falsely accepting the null hypothesis) or reduced power (60). Although there is no formal linkage between the global test adjustment (first approach) and the individual test adjustment (second approach), in most (but not all) explored cases, when there was global significance, there were also significant individual correlations and, when there was not global significance, there were no significant individual correlations (A. B. Kriss, data not shown).

Third, a separate ad-hoc method followed by Pietravalle et al. (41) was used to reduce the chances of falsely declaring a positive result due to spurious results (caused by unexplained variation and correlations). A significant positive relation during a given time period between an environmental variable and FHB intensity was declared only if there were clusters of successive correlations that were individually significant (at $P<0.005$ ). The individual significance levels were determined using the approach in the previous paragraph. The principle is that, because of the high correlation of the environment in nearby windows, as discussed previously, a single large correlation of environment with FHB intensity surrounded by small or 0 correlations would likely be a false positive. There is no formal (probabilistic or other) rule regarding the required length of correlation clusters; we chose clusters of five. We primarily used this third method to confirm the results of the global significance level (based on the Simes' method) for a given variable and window length.

It should be noted that the magnitude of the Simes' adjustment is a function of the number of test results in the collection being considered. In particular, the adjustment for short time windows is much greater than for long time windows. Thus, in general, individual correlations must be larger for short time windows than for long time windows in order for there to be a significant global test result.

Serial correlation for FHB. Trends in FHB intensity from year to year were characterized using (Spearman) serial correlations. After first ranking the data for each location, the ARIMA procedure in SAS was used to estimate the first-order correlation coefficient and its standard error.

\section{RESULTS}

Annual variation in disease intensity. There was considerable year-to-year heterogeneity in FHB intensity for Ohio, Indiana, Kansas, and North Dakota (Fig. 1). Although one cannot directly compare the magnitude of intensity values across locations (because of the different scales or types of measurements utilized), the large numbers of zeros for Kansas indicate that this location had the lowest amount of FHB. Within each state, disease intensity from year to year was highly variable, with low-moderate serial correlation between successive years. For instance, the firstorder serial Spearman correlations and their corresponding standard error was $0.304(0.15), 0.319(0.17),-0.104(0.20)$, and 0.314 (0.21) for Ohio, Indiana, Kansas, and North Dakota, respectively. The apparent decreasing trend in disease in North Dakota, starting $\approx 15$ years ago, was not supported by a significant correlation coefficient. Also, in any given year, disease intensity was variable among states. There were several years where high FHB intensity in one state did not coincide with high disease levels in other states, and vice versa. However, there was more similarity in FHB intensity between Ohio and Indiana, possibly because of the proximity of the states (Fig. 1).

Ohio window-pane analyses. In Ohio, yearly fluctuations of FHB intensity were significantly and positively correlated with several environmental variables. Table 3 provides the adjusted global $P$ value $\left(P_{g}\right)$ and the maximum individual Spearman correlation coefficient for each weather variable and window length. The table also indicates whether the maximum correlation was 
significant at an individual $P$ value $\leq 0.005$ and whether there was at least one cluster of five successive correlation coefficients that were significant. In general, variables that represented atmospheric moisture or wetness conditions in some sense (e.g., relative humidity and precipitation) were significantly and positively correlated with FHB intensity, and variables based on temperature alone were not. The mean ARH, for instance, was significantly correlated to FHB intensity for all window lengths $\left(P_{g} \leq 0.05\right)$. Also, there were clusters of at least five significant positive $r$ values at all window lengths of 10 to 240 days.

Individual Spearman correlation coefficients from the windowpane analysis are depicted in the form of graphs for each window length. The specific example of ARH is shown in Figure 2 for 10 different window lengths. (For the window length of 280 days, there is only a single window, encompassing the entire time frame). The horizontal axis represents the starting time of each window of a given length (where time 0 is the end of the season) and each vertical bar represents the (estimated) correlation coefficient for the association between FHB intensity and ARH for the given window. The number of bars depends on the length of the window (Table 1). For instance, there are 270 vertical bars for the 10-day windows; the first bar is at 0 , and the last is at time -270 (the first day of the last window calculated). For short window lengths (e.g., 10 to 30 days), ARH was significantly ( $P \leq$ 0.005 ) correlated with FHB intensity during and shortly before late May or mid-June ( -10 to -25$)$ and at approximately late April (-70), early March (-120), and late December (-185). At the 30-day window length (and longer), significant correlations could also be seen for windows at approximately the end of the season $(0$ to -15$)$. The time period from 0 to -25 days encompasses the approximate time of DON production and fungal colonization of the spike; -25 to -45 encompasses the approximate time of infection (anthesis and later); -45 to -120 encompasses the approximate time for inoculum production; and -120 to -220 encompasses the approximate time of pathogen winter survival (57).
For ARH, as the window length increased, the individual correlation coefficients and the maximum coefficient across all window start times tended to decrease (Fig. 2; Table 3). However, the global Simes'-based test was significant at all window lengths. Maximum daily relative humidity (MRH), average negative daily dew point depression (NDPD), and hours with relative humidity $>80 \%$ (HRH80) (Table 2) showed similar trends as found with ARH (Table 3), although the $P_{g}$ values were slightly $>0.05$ for a few window lengths. Because of the similarity of results to that found for $\mathrm{ARH}$, individual correlation coefficients are not shown for these variables. Interestingly, hours of relative humidity $>90 \%$ (HRH90) were not significantly correlated with FHB intensity $\left(P_{g}>0.05\right)$, although there were some significant individual correlations $(P \leq 0.005)$ for shorter time windows.

Precipitation variables were also significantly correlated with FHB intensity in Ohio $\left(P_{g} \leq 0.05\right.$, individual $\left.P \leq 0.005\right)$ for selected window lengths. The total daily amount of precipitation (TP) was significantly associated with FHB intensity for 15- and 30-day windows, and the incidence of precipitation (IP) was significantly associated with FHB intensity for 15- to 210-day windows (Table 3). Each of these variables had clusters of five or more sequential $r$ values that were individually significant. The correlation coefficients at four selected window lengths are shown in Figure 3A to demonstrate the patterns. The highest correlations were predominantly located at starting times from 0 to -30 (Fig. $3 \mathrm{~A}$ ), which includes anthesis through crop maturation. In general, the magnitude of the correlations decreased as the window length increased to $>60$ days.

Temperature-based variables that were not coupled with aspects of moisture or wetness, such as AT, were not significantly correlated $\left(P_{g}>0.05\right.$, individual $\left.P>0.005\right)$ with annual FHB intensity for any time window (Fig. 3B; Table 3). The same nonsignificant results were found for the T1530, DD15, DD9, NDD15, and NDD9 temperature variables (Table 2), and the tabular and graphic results are not displayed for these latter variables to save
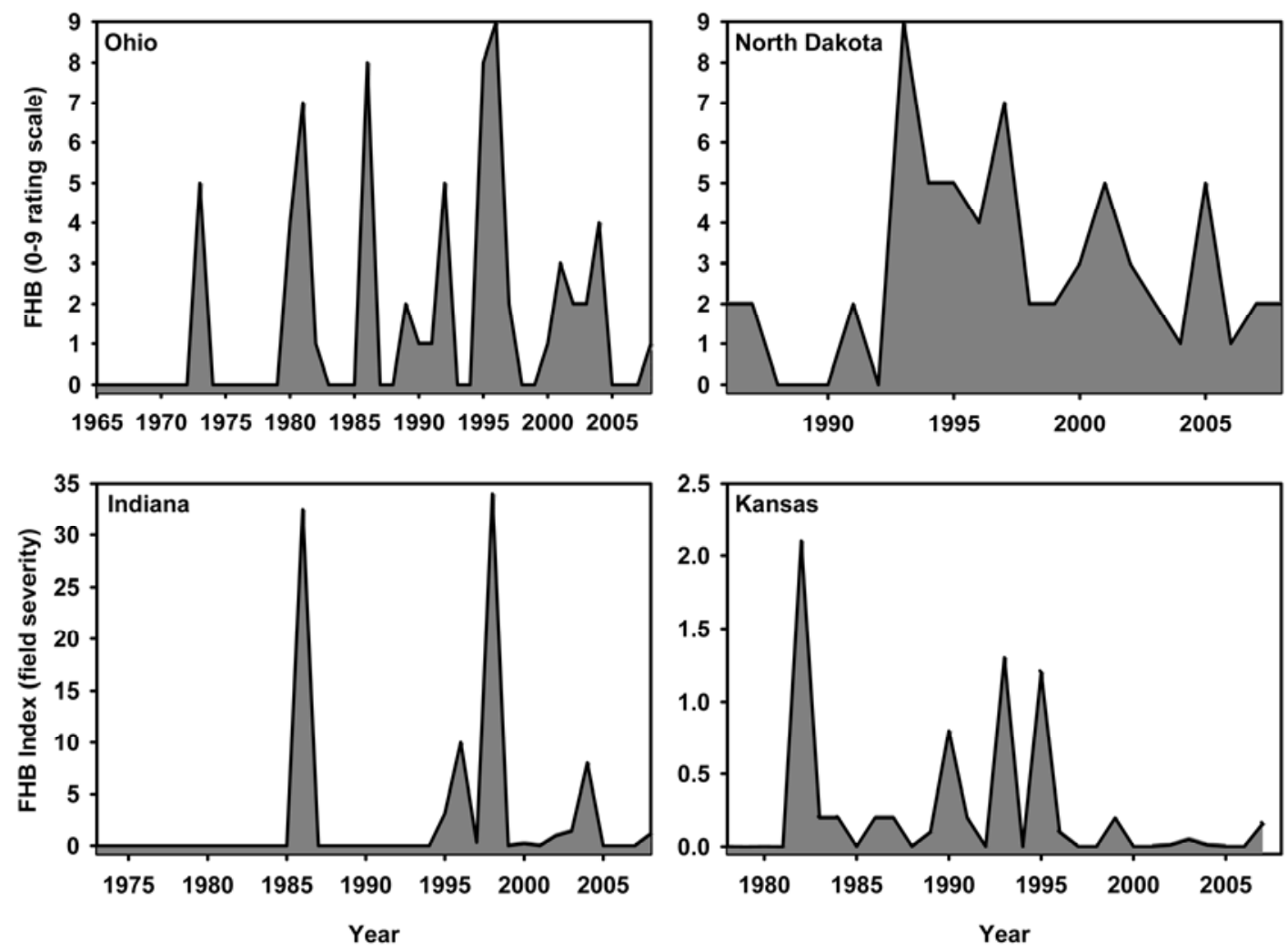

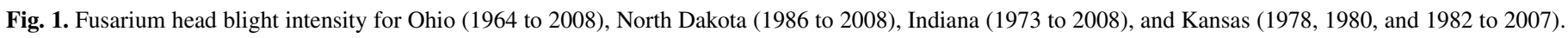
Disease assessment scale was different among the four locations. 
space. On the other hand, when temperature was coupled with other variables to create a composite environmental variable, such as the number of hours with relative humidity $>80 \%$ and temperature of 15 to $30^{\circ} \mathrm{C}$ (THRH80) (Table 2), significant correlations were found at several window lengths (Table 3; Fig. 3C). For THRH80, at short window lengths (10 and 15 days), the maximum correlation coefficients were slightly lower than those found when temperature was not incorporated into the corresponding environmental variable. However, at window lengths $\geq 30$ days, the maximum correlations were substantially higher when temperature was considered jointly with relative humidity than when temperature was not considered. In fact, for window lengths $\geq 120$ days, the maximum correlation coefficients for THRH80 were higher than the maximum for any other variable at these long window lengths (Table 3). Similar to previously mentioned moisture variables, the highest correlations between FHB intensity and THRH80 were near anthesis, with other moderately high correlation coefficients at time -70 (Fig. 3C). Results for the composite variable T1530P were similar to those found without the use of temperature (IP), and individual test results are not shown.

A graphic depiction of the time windows with individually significant correlation coefficients (at $P \leq 0.005$ ) is provided in Figure 4 for two shorter window lengths. The variables AT and THRH90 are not included in the summary because of their general lack of significant associations with FHB intensity in Ohio. The horizontal lines encompass the time range of the windows with significant correlations between the environmental variable and FHB intensity, not just the starting time of the windows. As shown in the first row of graphs, substantial portions of the late season (anthesis to approximate maturity) had significant correlations, although the exact times varied a little. For relative humidity variables, the earlier time periods with high correlations are also evident (as shown more specifically in Figure 2 for ARH).

Indiana, Kansas, and North Dakota window-pane analyses. Results similar to those found in Ohio were also found in the three other states. In each location, environmental variables based on atmospheric moisture or wetness conditions (e.g., ARH and HRH80) tended to be positively correlated to FHB intensity $\left(P_{g} \leq\right.$ 0.05 ) for one or more windows (Table 4), especially for windows of shorter length ( $\leq 60$ days). At least two moisture or wetness variables were significant for each location. There were fewer globally significant results for North Dakota, possibly because of the smaller number of years in the analysis, which can have a large impact on the power to detect a true positive correlation (65). For this state, several of the results of the Simes' tests were borderline significant (i.e., $0.05 \leq P_{g} \leq 0.10$ ).

Although there were a few exceptions, maximum correlation for a given variable tended to be highest-and individually significant at $P \leq 0.005$ - at one of the shorter window lengths $(10,15,30$, or 60 days), and the magnitude of the correlation coefficients generally declined as window lengths increased to $>60$ days. Thus, to save space, only the results for five window lengths are shown in Table 4.

Based on global significance level, $P_{g}$, in these three states, there were no significant correlations found between the temperature-only variables and FHB intensity for any time window (Table 4). The results were the same for the other temperature-only variables listed in Table 3 (A. B. Kriss, data not shown). In Indiana, however, a few individual correlations with the 10- and 15-day window lengths were found to be significant (individual $P \leq 0.005$ ), although there were no clusters of five or more individually significant correlations involving temperature (Table 4). As in Ohio, incorporating temperature into a moisture variable (e.g., THRH80) did generally increase the magnitude of the correlations found for HRH80 with the different time windows.

In terms of the overall results across all starting times of the windows, some specific differences between the states could be seen (Tables 3 and 4). For Indiana, the smallest $P_{g}$ and largest maximum $r$ (over all the starting times) were found for 60-day windows for several variables (ARH, MRH, NDPD, TP, and IP), whereas shorter windows tended to have the smallest $P_{g}$ and largest maximum $r$ for the other locations (including Ohio). Also, the highest correlations (across all variables and window lengths) tended to be higher for Kansas and North Dakota compared with

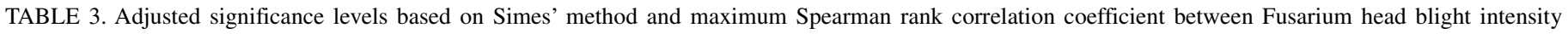
rating and environmental variables for listed time window lengths based on 44 years of data from Ohio ${ }^{\mathrm{a}}$

\begin{tabular}{|c|c|c|c|c|c|c|c|c|c|c|c|}
\hline \multirow[b]{2}{*}{ Variable $^{b}$} & \multicolumn{11}{|c|}{ Significance level for window length (days) } \\
\hline & 10 & 15 & 30 & 60 & 90 & 120 & 150 & 180 & 210 & 240 & 280 \\
\hline \multicolumn{12}{|l|}{$P_{g}$} \\
\hline ÁT & 0.713 & 0.681 & 0.496 & 0.456 & 0.296 & 0.201 & 0.242 & 0.311 & 0.292 & 0.24 & 0.473 \\
\hline ARH & 0.006 & 0.006 & 0.005 & 0.010 & 0.005 & 0.005 & 0.004 & 0.004 & 0.004 & 0.008 & 0.012 \\
\hline MRH & 0.033 & 0.027 & 0.022 & 0.015 & 0.010 & 0.009 & 0.009 & 0.009 & 0.013 & 0.012 & 0.018 \\
\hline NDPD & 0.019 & 0.011 & 0.033 & 0.03 & 0.071 & 0.062 & 0.048 & 0.047 & 0.064 & 0.058 & 0.062 \\
\hline $\mathrm{TP}$ & 0.257 & 0.037 & 0.005 & 0.095 & 0.172 & 0.115 & 0.041 & 0.135 & 0.223 & 0.110 & 0.148 \\
\hline IP & 0.064 & 0.004 & $<0.001$ & $<0.001$ & $<0.001$ & $<0.001$ & 0.002 & 0.012 & 0.040 & 0.059 & 0.056 \\
\hline HRH90 & 0.095 & 0.125 & 0.074 & 0.089 & 0.100 & 0.084 & 0.123 & 0.124 & 0.117 & 0.094 & 0.162 \\
\hline THRH90 & 0.161 & 0.135 & 0.184 & 0.141 & 0.091 & 0.080 & 0.067 & 0.056 & 0.053 & 0.036 & 0.054 \\
\hline HRH80 & $<0.001$ & $<0.001$ & 0.002 & 0.018 & 0.048 & 0.026 & 0.037 & 0.046 & 0.067 & 0.067 & 0.080 \\
\hline THRH80 & 0.015 & 0.001 & $<0.001$ & 0.001 & $<0.001$ & $<0.001$ & $<0.001$ & $<0.001$ & $<0.001$ & $<0.001$ & 0.004 \\
\hline \multicolumn{12}{|l|}{ Spearman $^{c}$} \\
\hline AT & 0.326 & 0.277 & 0.305 & 0.315 & 0.293 & 0.273 & 0.274 & 0.261 & 0.161 & 0.153 & 0.111 \\
\hline ARH & $0.554 *$ & 0.559* & $0.532 *$ & $0.521 *$ & 0.491* & $0.496 *$ & $0.481 *$ & $0.468 *$ & $0.456 *$ & $0.424 *$ & 0.374 \\
\hline MRH & $0.484 *$ & 0.459* & $0.442 *$ & $0.462 *$ & $0.436 *$ & $0.432 *$ & $0.419 *$ & $0.408 *$ & $0.395 *$ & 0.367 & 0.355 \\
\hline NDPD & $0.527 *$ & $0.558 *$ & $0.519 *$ & $0.471 *$ & $0.435 *$ & $0.414 *$ & $0.395 *$ & 0.373 & 0.378 & 0.322 & 0.284 \\
\hline $\mathrm{TP}$ & $0.435^{*}$ & $0.522 *$ & $0.577 *$ & 0.419* & 0.381 & 0.381 & $0.443 *$ & 0.344 & 0.315 & 0.309 & 0.222 \\
\hline IP & $0.470^{*}$ & $0.573 *$ & $0.609 *$ & $0.677 *$ & 0.638* & $0.587 *$ & $0.541 *$ & $0.463^{*}$ & $0.405 *$ & 0.338 & 0.290 \\
\hline HRH90 & $0.413 *$ & $0.427 *$ & $0.416 *$ & $0.416 *$ & 0.373 & 0.349 & 0.353 & 0.296 & 0.264 & 0.251 & 0.215 \\
\hline THRH90 & $0.450 *$ & $0.431 *$ & $0.396^{*}$ & $0.399 *$ & $0.391 *$ & $0.392 *$ & $0.392 *$ & $0.388^{*}$ & 0.382 & 0.374 & 0.292 \\
\hline HRH80 & 0.618* & $0.666^{*}$ & $0.567 *$ & 0.458* & $0.406 *$ & 0.448* & $0.418 *$ & 0.375 & 0.364 & 0.315 & 0.267 \\
\hline THRH80 & $0.549 *$ & $0.596^{*}$ & $0.658 *$ & $0.606^{*}$ & $0.609 *$ & $0.627 *$ & $0.627 *$ & $0.621 *$ & $0.606^{*}$ & $0.555^{*}$ & $0.421 *$ \\
\hline
\end{tabular}

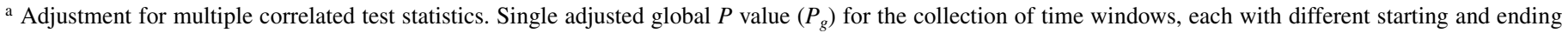
dates, of the listed window lengths. Values of $P_{g}<0.05\left(\alpha_{g}\right)$ are considered significant.

b Variables are defined in Table 2.

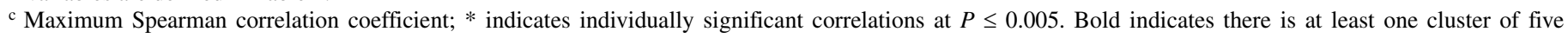
contiguous correlation coefficients with individual $P$ values $\leq 0.005$. 
Ohio or Indiana. The largest correlations found per location (among all variables) were $0.677,0.681,0.787$, and 0.704 for Ohio, Indiana, Kansas, and North Dakota. Moreover, based on the global test, the atmospheric-moisture-based MRH and NDPD were not significant $\left(P_{g}>0.05\right)$ for Kansas, although these were significant globally for the other locations; also, rainfall-based TP and IP were not significant for North Dakota, although they were significant elsewhere.

The individual correlation coefficients for three select environmental variables (ARH, TP, and THRH80), chosen for demonstration purposes, and two (short) window lengths are shown in Figure 5. For ARH at a short window length (15 days), there were high and individually significant $(P \leq 0.005)$ positive correlations $\approx-10$ and -45 in Indiana; -35 in Kansas; and $-20,-120$, and
-180 in North Dakota (Fig. 5A). At the somewhat longer window length (30 days), there were high and individually significant $(P \leq$ 0.005 ) positive correlations $\approx-30$ in Indiana and Kansas (Fig. 5B). Similar patterns were found for the TP variable, with high and significant correlations $\approx-30$ to -45 in Indiana and -25 to -40 in Kansas (Fig. 5C and D) but with no significant correlations in North Dakota. However, some of the correlations $\approx-25$ and -30 were very close to being significant at $P \leq 0.005$. With 30 -day window lengths, significant positive correlations were found for at approximately the same time periods as found for the 15-day windows, and the correlations for North Dakota were also significant. For THRH80, the highest correlations corresponded to the time near crop maturity (for either window length). In Indiana, these high positive correlations were $\approx-10$ and, in
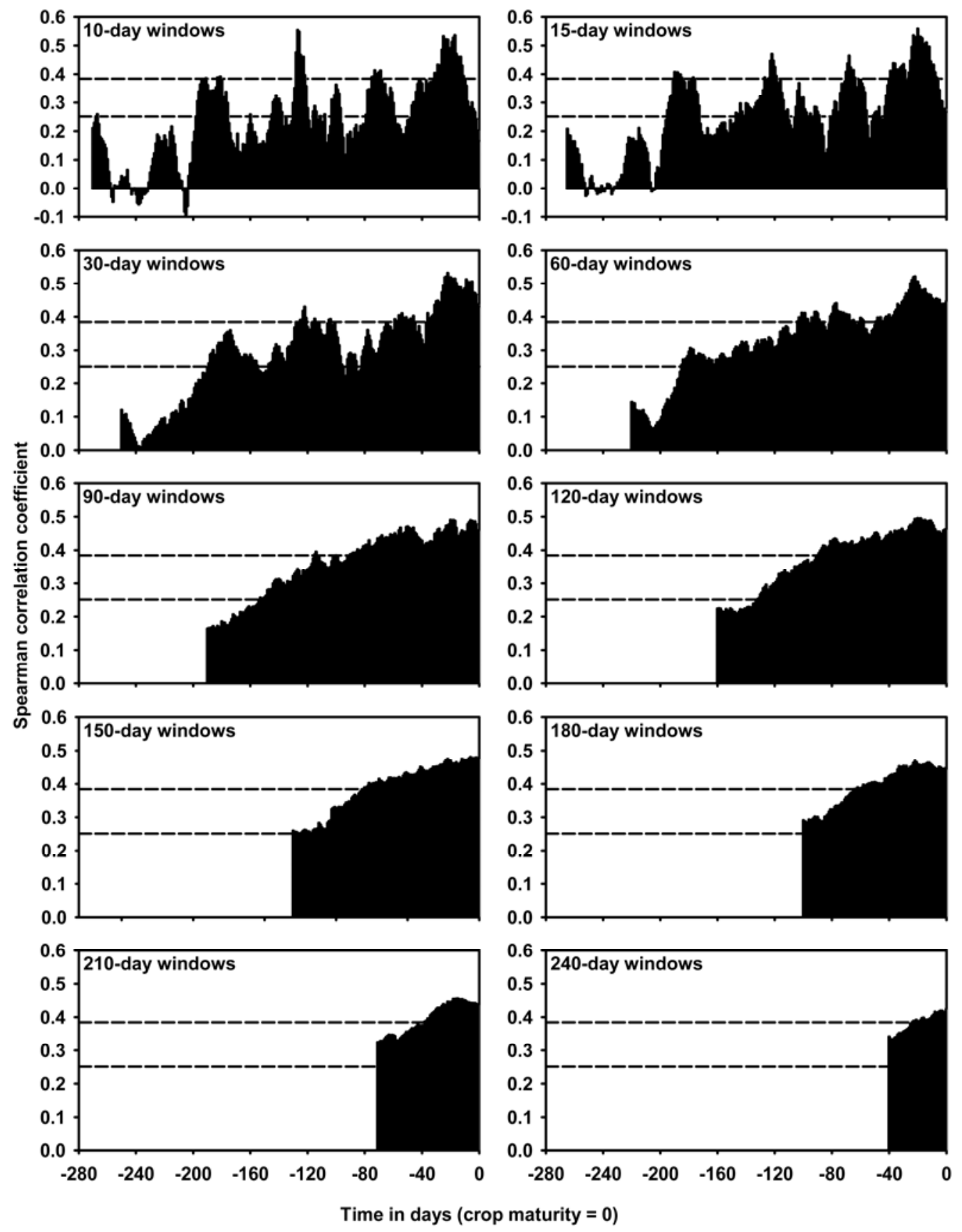

Fig. 2. Spearman rank correlation coefficients for the association between average daily relative humidity (ARH) and Fusarium head blight intensity in Ohio. Window lengths of 10 to 240 days are shown in separate graphs. Horizontal axis represents the starting time of the window of defined length, with day 0 representing 30 June and day -280 representing 24 September. Horizontal lines are at the critical correlation coefficients for individual significance at $\alpha=0.005$ and 0.05 . Critical correlation for $\alpha=0.05$ does not provide any adjustment for multiple correlated test statistics and critical correlation for $\alpha=0.005$ provides some adjustment for the multiple statistics. 
Kansas, $\approx 0$ to -10 (Fig. $5 \mathrm{E}$ and F). In North Dakota, the high correlations were $\approx 0$ to -20 . It should be noted that, even when a variable did not have a significant association with FHB intensity globally (across all window starting times; $P_{g} \leq 0.05$ ), there could still be individual positive correlation coefficients that were significant at $P \leq 0.005$.

The similarity of the individual correlation results across locations can be seen graphically in Figure 4 for eight of the environmental variables. With the 30-day window length, the significant positive correlation coefficients between environment and FHB intensity near the end of the growing season (from shortly before anthesis to crop maturity) can be clearly seen for most of these moisture- or wetness-related variables. There were just a few noticeable differences among the locations. In Kansas, the significant correlations did not extend as close to time 0 as they did in the other locations. This may be due to the earlier

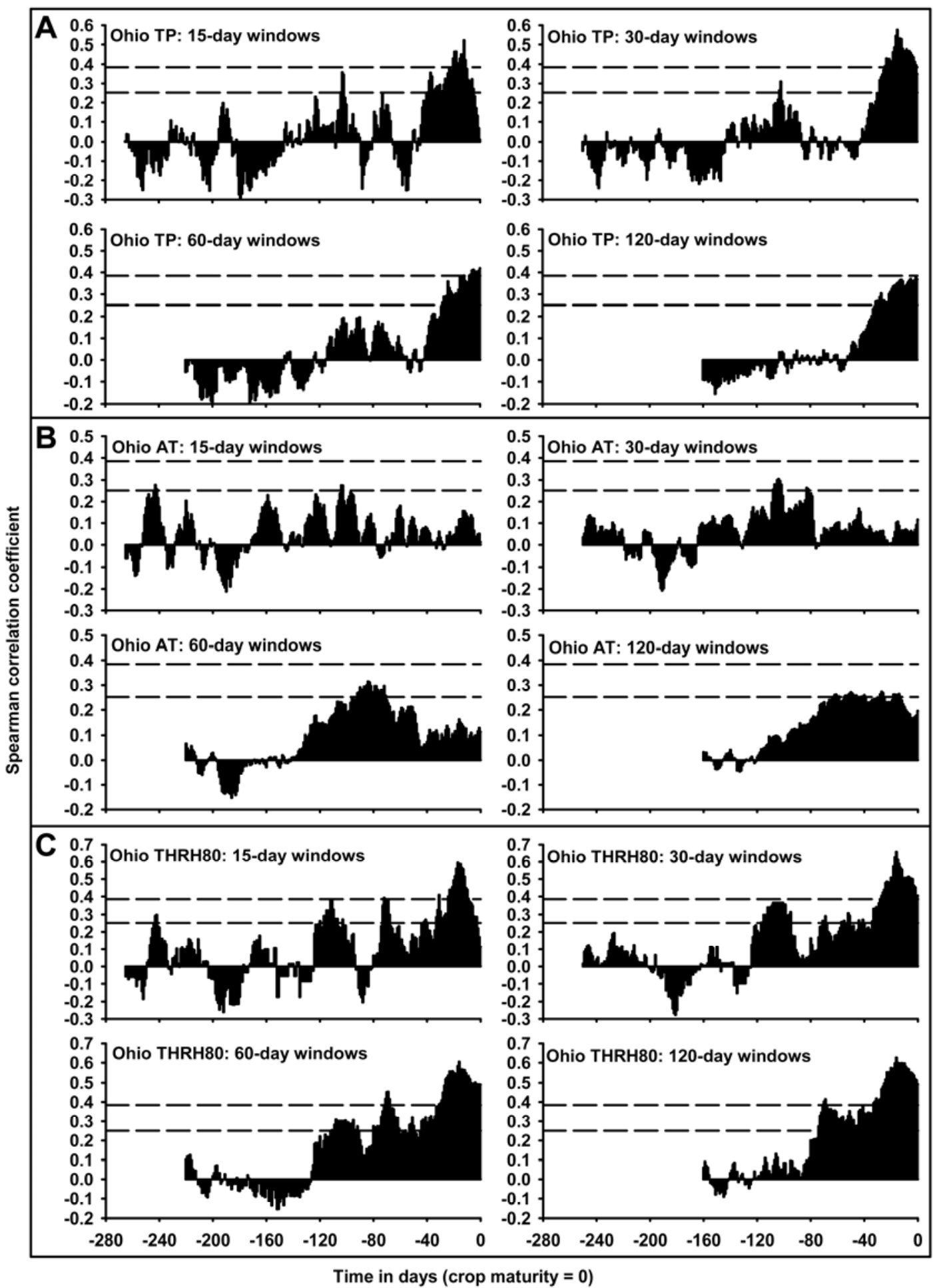

Fig. 3. Spearman rank correlation coefficients for the association between $\mathbf{A}$, total daily precipitation (TP); $\mathbf{B}$, average daily temperature (AT); and $\mathbf{C}$, number of hours with temperature of 15 to $30^{\circ} \mathrm{C}$ and mean relative humidity $>80 \%$ (THRH80), and Fusarium head blight intensity in Ohio. Window lengths of 15,30 , 60, and 120 days are shown for each environmental variable. Horizontal axis represents the starting time of the window of defined length, with day 0 representing 30 June and day -280 representing 24 September. Horizontal lines are at the critical correlation coefficients for individual significance at $\alpha=0.005$ and 0.05 . Critical correlation for $\alpha=0.05$ does not provide any adjustment for multiple correlated test statistics and critical correlation for $\alpha=0.005$ provides some adjustment for the multiple statistics. 
flowering dates of wheat in Kansas compared with the other states (relative to the chosen time for crop maturity). In North Dakota, fewer of the variables were significant (at $P \leq 0.005$ ) compared with the other states. The variable HRH90 (Table 2) was individually significant late in the season only in Ohio (although it was not globally significant here), and MRH was significant late in the season only in Indiana. Moreover, only in Ohio and North Dakota were there significant correlations at starting times of $\approx-100$ or earlier (for a small number of variables).

With 15-day window lengths, greater temporal resolution could be seen in the timing of significant correlation coefficients, with more periods of noncontiguous high correlations being evident
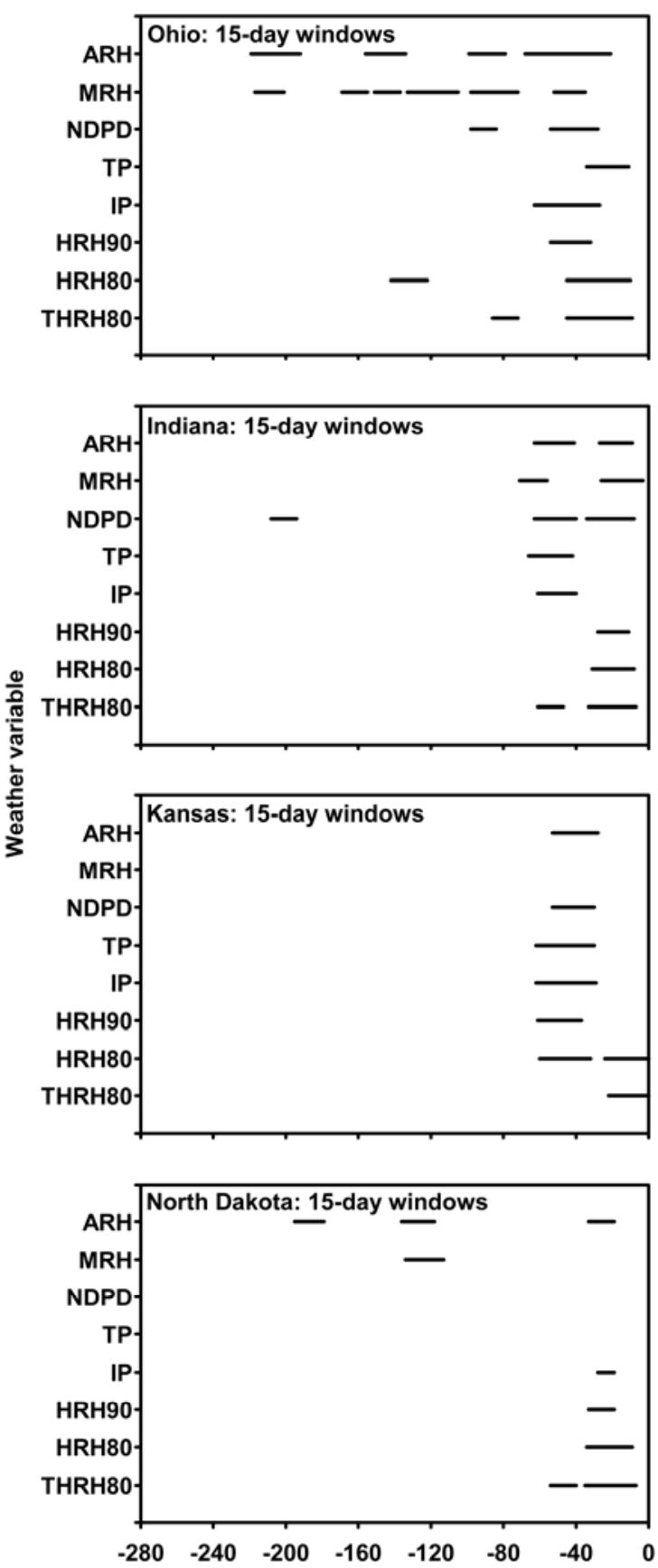

(relative to the 30-day windows). In Ohio and North Dakota, there also were more periods before day -80 with high correlations. With the higher resolution, the positive correlations near or right before anthesis were evident for most locations, at least for several variables. The very late-season correlations (near crop maturity) found with 30-day windows were less evident with 15day window lengths.

\section{DISCUSSION}

A window-pane analysis (11) based on use of the nonparametric Spearman correlation coefficient (55) was used in the
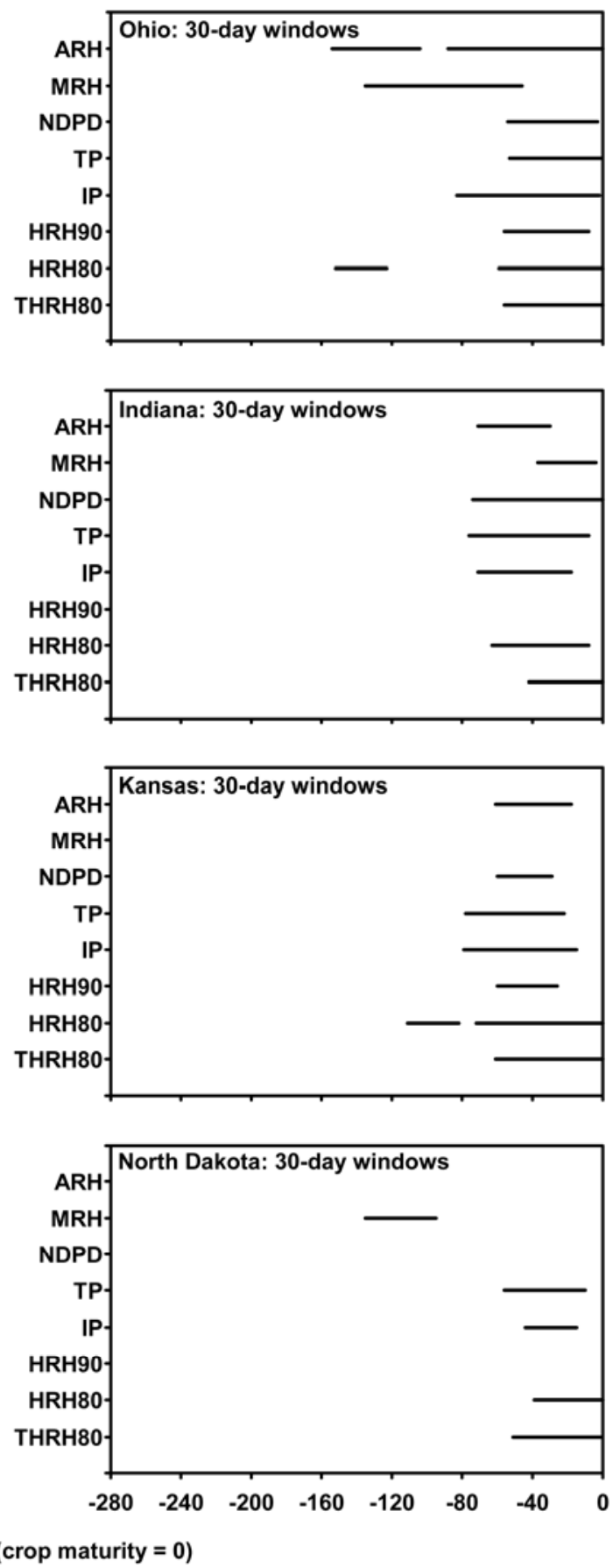

Fig. 4. Graphic summary of the time periods in which there were significant positive correlation coefficients between each of eight environmental variables (see Table 2) and Fusarium head blight (FHB) intensity (with individual correlations significant at $P \leq 0.005$ ) in four locations (states). Results are shown for 15- and 30-day window lengths. Time line corresponds to days prior to 30 June (time 0) for Ohio, Indiana, and Kansas and days prior to 15 August for North Dakota. Lines encompass the total time of a window where the summary variable (e.g., average relative humidity [ARH] for 15 days) was significantly related to FHB intensity, not just the starting time of the window. For instance, if ARH was significant with a 15-day window starting on day -20 , then the line would go from -20 to -34 . In contrast, Figures 2, 3, and 5 identify the starting time of each window. 
current investigation to identify environmental variables that were associated with annual fluctuations of FHB intensity. As with any type of correlation analysis, the power to detect significant relationships is a function of the number of observations; thus, the power (for an environmental variable that truly was associated with FHB intensity) would be highest for Ohio $(n=44)$, followed by Indiana $(n=36)$, Kansas $(n=28)$, and, finally, North Dakota $(n=23)$. Equivalently, the magnitude of $r$ required to reject the null hypothesis in favor of the alternative (at a specified $\alpha$ ) is inversely related to $N$; for instance, a much larger $r$ was required for North Dakota than for Ohio to declare a significant positive correlation (at a fixed $\alpha$ ). Nevertheless, results for North Dakota were generally similar to those in the other states, although there were fewer significant correlation coefficients.

In all states, there was no evidence of a significant correlation between FHB intensity and any of the temperature variables (e.g., AT) for any time window. This may initially be considered surprising given that others $(1,21,57)$ have shown that various components of the pathogen life cycle (e.g., rate of sporulation and spore density on spikes) are dependent on temperature. However, in the absence of wetness (from rain or dew) or high atmospheric moisture levels (e.g., high relative humidity), temperature alone may be relatively unimportant for the disease. Moreover, during critical portions of the season (e.g., near anthesis), temperature may not vary enough from year to year within a location for there to be a detectable level of association of temperature variables with FHB intensity. Based on other diseases of field crops, temperature variables alone may be of greatest potential value in predicting overwintering of the pathogen (56). However, the correlations during for the winter months were low and also not significant here.

As anticipated from several other studies $(19,33,38,44)$, moisture- or wetness-related variables (e.g., ARH and TP) were found to be significantly correlated with FHB intensity over the multiple years of observations in Ohio and the other locations. Additionally, variables that combined aspects of moisture or wetness with temperature (e.g., TRH80) were also correlated with FHB intensity and, sometimes, the estimated correlation coefficients were higher when temperature was incorporated into the moisture or wetness variable than when it was not. In general, the $r$ values were higher for the shorter window lengths (e.g., 15 or 30 days) than for the longer lengths (e.g., $\geq 120$ days). Moreover, with the shorter time windows, the highest positive correlations were found for time periods from $\approx 60$ days before crop maturity (time $-60)$ to approximately crop maturity (time 0 ), with the exact results dependent on location and the window length. With 15-day window lengths, there were more distinct time windows identified with high $r$ values, and correlations very late in the season ( -10 to 0 ) were usually not significant (Fig. 4). This would suggest that the high correlations for windows that included time 0 - found with the 30-day window-were based more on the environmental conditions $>10$ days before maturity rather than the conditions immediately before or at time 0 . The results of moisture or wetness effects on disease development support the findings of several other authors $(7,14,19,31,38,44)$. In particular, the high correlations from $\approx-60$ to -30 days likely reflect the influence of atmospheric moisture on production of ascospores and conidia in debris, and the subsequent dispersal to wheat spikes (57). In this regard, Gilbert et al. (24) found the rate of ascospore germination was at a maximum at $90 \%$ relative humidity, and Paul et al. (38) found that moisture-related variables had a significant relationship with spore density on wheat spikes immediately before, at, and after anthesis. High correlations from $\approx-40$ to -10 days likely represent the influence of moisture or wetness variables (or combined moisture and temperature variables) on infection efficiency of spores and spike colonization (with DON production) $(7,14$, 57). De Wolf et al. (19) found that the combined effect of temperature and moisture or wetness was related to FHB disease risk during the time periods for sporulation and spike infection. However, they found that the number of hours that temperature was 15 to $30^{\circ} \mathrm{C}$ and relative humidity was $\geq 90 \%$ had a stronger relationship than the number of hours with a temperature 15 to

TABLE 4. Adjusted significance levels based on Simes' method and maximum Spearman rank correlation coefficient between Fusarium head blight intensity rating and environmental variables for 10-, 15-, 30-, 60-, and 120-day window lengths based on data from Indiana, Kansas, and North Dakota ${ }^{\mathrm{a}}$

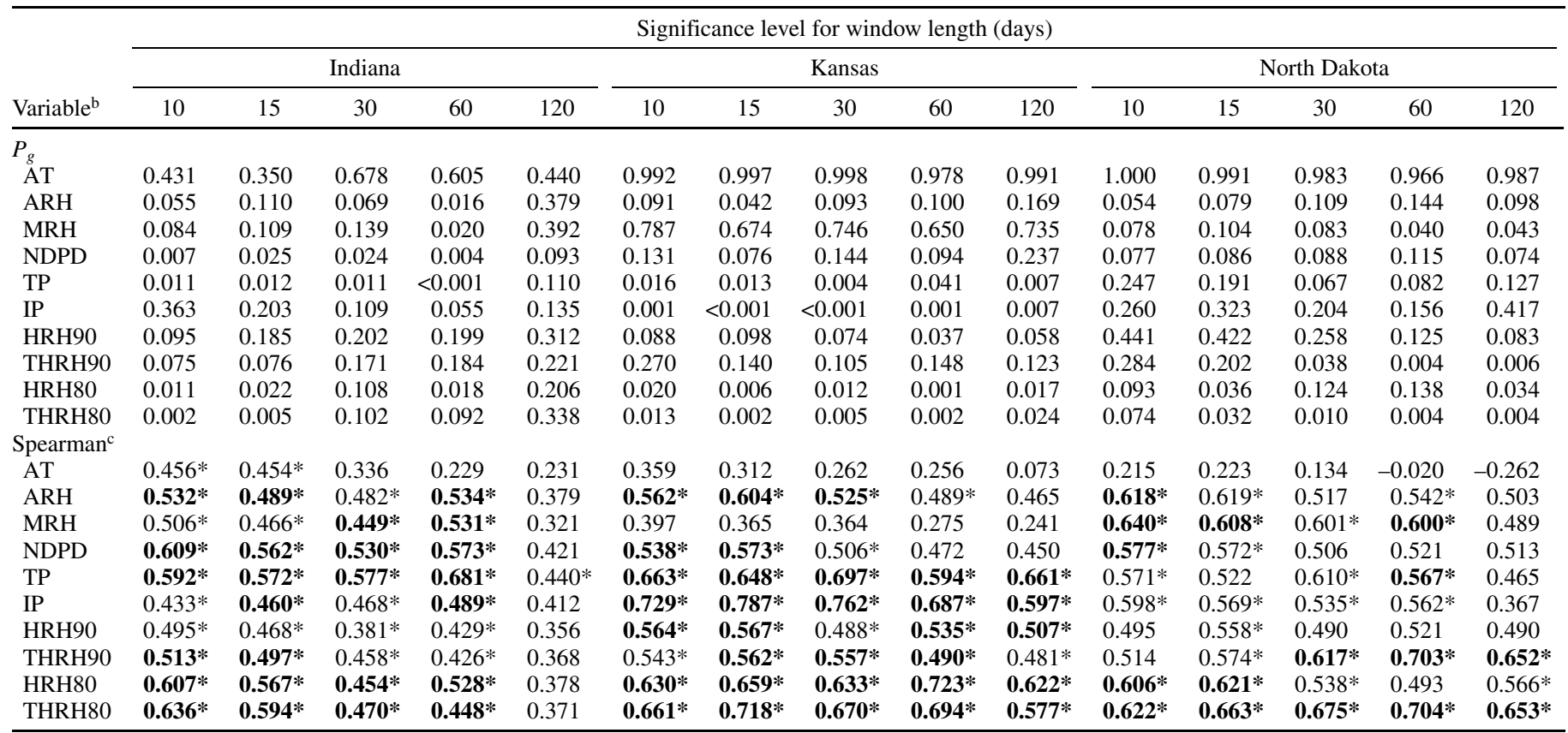

a Adjustment for multiple correlated test statistics. Single adjusted global $P$ value $\left(P_{g}\right)$ for the collection of time windows, each with different starting and ending dates, of the listed window lengths. Values of $P_{g}<0.05\left(\alpha_{g}\right)$ are considered significant.

b Variables are defined in Table 2.

${ }^{\mathrm{c}}$ Maximum Spearman correlation coefficient; * indicates individually significant correlations at $P \leq 0.005$. Bold indicates there is at least one cluster of five contiguous correlation coefficients with individual $P$ values $\leq 0.005$. 
$30^{\circ} \mathrm{C}$ and relative humidity $>80 \%$. In the present study, using different data, we find the opposite to be true. In the current study, this may reflect lower accuracy of relative humidity observations from some weather stations, where hourly relative humidity was determined using a standard formula based on measured air temperature and dew point. The accuracy of these measurements is $\approx \pm 1{ }^{\circ} \mathrm{C}$, which can lead to decreasing (relative) accuracy as relative humidity approaches $100 \%$.

No single best environmental variable was identified in this investigation for its correlation with FHB intensity; rather, several intercorrelated moisture or wetness variables were found to give very similar results. This is not surprising because the environ- mental variables were correlated with each other. Furthermore, as discussed above, no single window length (for starting times between -60 and 0 ) was best overall, although shorter windows (60-day and, especially, 30- and 15-day) generally gave the highest correlations compared with longer windows (especially $\geq 120$ days). The general decline in individual correlation coefficients (at particular window starting times), or decline in the maximum correlation for a particular location (across all starting times), with increasing window lengths suggests that FHB intensity is affected more by shorter-term weather patterns than by longer-term climatic conditions (over multiple months). The shorter window lengths can be more directly connected to

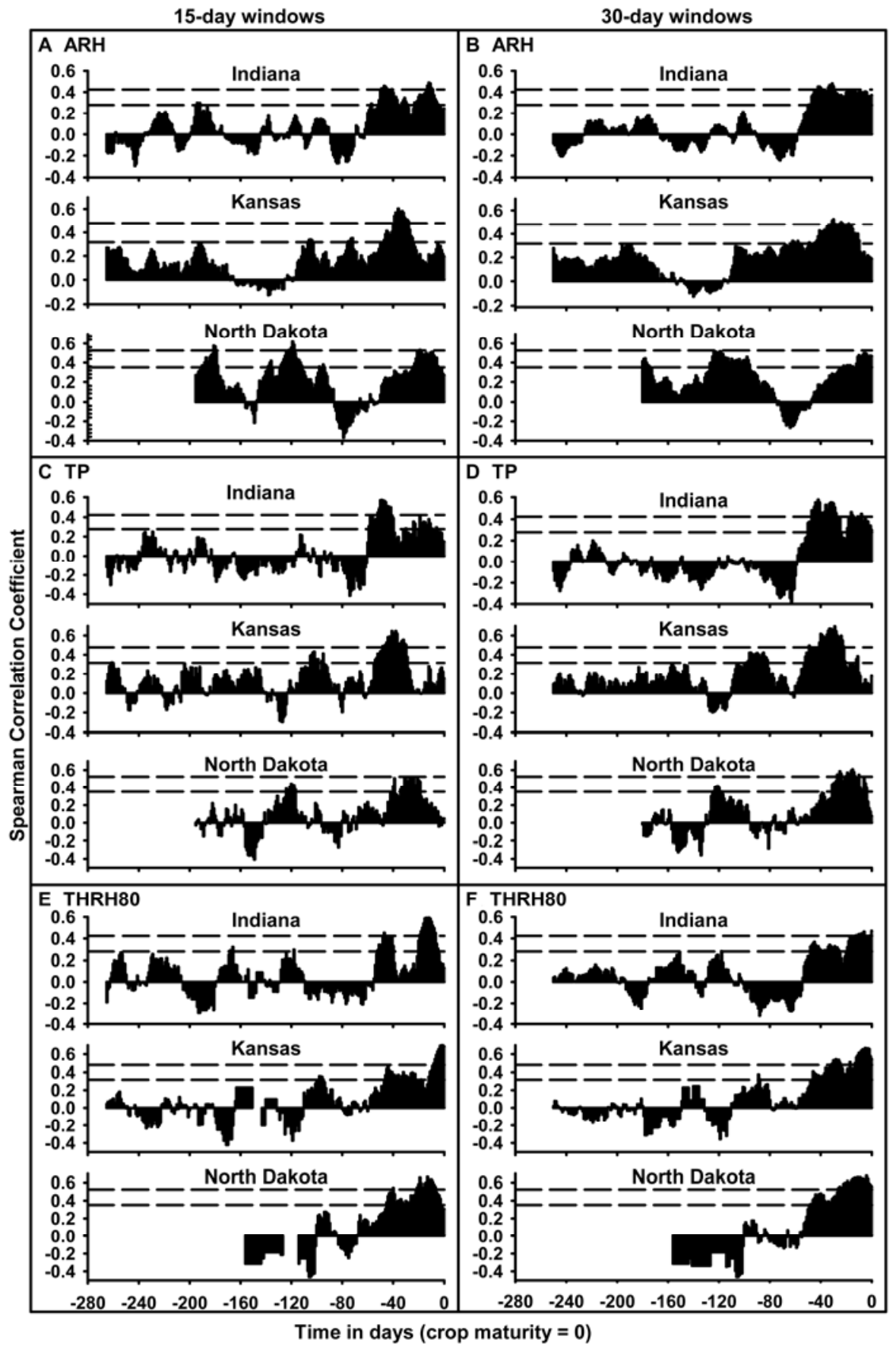

Fig. 5. Spearman rank correlation coefficients for the association between $\mathbf{A}$, average daily relative humidity (ARH) at 15-day windows; $\mathbf{B}$, average daily relative humidity (ARH) at 30-day windows; total daily precipitation (TP) at $\mathbf{C}, 15$-day and $\mathbf{D}, 30$-day windows; and number of hours that temperature was 15 to $30^{\circ} \mathrm{C}$ and the mean relative humidity was $>80 \%$ (THRH80) at E, 15-day and F, 30-day windows, and Fusarium head blight intensity in Indiana, Kansas, and North Dakota. Horizontal axis represents the starting time of the window of defined length, with day 0 representing 30 June and day -280 representing 24 September. Horizontal lines are at the critical correlation coefficients for individual significance at $\alpha=0.005$ and 0.05 . Critical correlation for $\alpha=0.05$ does not provide any adjustment for multiple correlated test statistics and critical correlation for $\alpha=0.005$ provides some adjustment for the multiple statistics. 
particular crop stages and components of the disease cycle, as discussed above. Ideally, window length could be refined further, especially by further shortening of the window length, by linking window start or end times to the timing of particular growth stages (e.g., anthesis) in a given location. However, with this system and available data, such additional refinement is not possible because: growth-stage timing (such as anthesis) varied somewhat within a region, cultivars varied with regard to the time when stages were reached, and there was no recording of the exact time of various crop growth stages in many location-years. Therefore, as window length decreased (with starting times based on a calendar date), there would be an increasing likelihood that the (very) short windows would line up with crop growth stages in some years and not others or for some cultivars and not others. Thus, window lengths of 15 or 30 days, or possibly 60 days in some circumstances, appeared to be the most appropriate time lengths for relating environment to FHB intensity in this multiyear and multilocation investigation.

Perhaps the most surprising result was the identification of significant correlation coefficients for some moisture-related variables for time windows considerably before anthesis in Ohio and North Dakota (at times of $\approx-160,-185$, or earlier) (Fig. 4). However, Lu et al. (31) also reported on significant relationships between FHB intensity and moisture- or wetness-related variables in the fall or winter (times of $\approx-150$ or -210 ). The correlations in our investigation may reflect a true relationship between wintertime environmental variables and pathogen winter survival. Alternatively, the results could reflect high autocorrelation of environmental variables over long time spans. For instance, the high correlation between FHB intensity and ARH at -185 could be (partly) due to a high correlation between ARH at -185 and -20 (the window near anthesis). Further investigations are needed to clarify the role of very early environmental conditions on FHB.

We used the Simes' multiplicity-adjustment procedure to test the global null hypothesis of no effect of an environmental variable across all windows of a particular length, primarily because it performs well with positively correlated test statistics (27). Where there was a significant result based on the Simes' procedure (i.e., $P_{g} \leq \alpha_{g}$, with $\alpha_{g}=0.05$ ), one to several individual correlations generally were found to be individually significant at $P \leq 0.005$ during the time periods identified above. Exceptions to the linkages of the different multiplicity corrections could be explained in terms of the degree of adjustment in the Simes' method for global hypothesis testing. The magnitude of the adjustment was very small with the very long window lengths because there were few separate $P$ values in the collection (in the extreme, with the 280-day window, there was only one individual $P$ value). Therefore, for some long window lengths, sometimes the global test was significant but individual correlations were not significant (at $P \leq 0.005$ ) (A. B. Kriss, data not shown). A less conservative individual $P$ value could be warranted in these cases but we did not pursue this because the estimated correlation coefficients generally declined in magnitude with increasing window length. With short window lengths, there are many $P$ values $>280$-day time frame, and the Simes' adjustment is correspondingly large; that is, the evidence has to be very strong for one or more positive correlations in a collection of correlations in order to reject the global null hypothesis. Thus, occasionally, the global test was not significant even though there were one or more individual correlations significant at $P \leq 0.005$. This was most likely to occur for the North Dakota data, partly because of the smaller number of years in the analysis compared with the other locations.

In conclusion, annual variations in FHB intensity were associated with several interrelated variables that summarized environmental conditions related to moisture and wetness over window lengths of various durations but especially shorter-length windows in the 2 months prior to crop maturity. Results were generally consistent with previously shown or postulated effects of environment on components of the disease cycle $(14,21,24)$. Furthermore, the correlation results support the use of real-time disease forecasting systems based on environmental conditions $(17,19)$ for this sporadic disease. The findings of this investigation can be used as a guide in determining possible updates to the current national FHB forecaster. Because the models in the national forecaster are based on data from a short 7-day window ending at anthesis, use of this system requires an estimate of the time of anthesis (19). This is one of the major challenges in use of the system $(17,29)$ because time of anthesis is less routinely determined or reported than time of heading. It is unknown how forecaster accuracy suffers when the anthesis time is misspecified. The current investigation showed that it may be feasible to use environmental summaries from less strictly defined window start or end times (relative to a single phenological wheat stage) to identify disease risk, and to use windows either closer to crop maturity or of longer lengths than currently used. Anthesis is approximately the latest time that a fungicide can be applied for FHB control. However, forecasts closer to crop maturity can be of benefit for estimating the magnitude of yield loss or DON contamination before the crop is harvested or sold at grain elevators. Because environment has been determined to be a significant factor in disease development, future work could include the use of climatic models (25) to predict years with high probability of moisture or wetness events during critical time windows. Climate models generally deal with longer-term environmental summaries (of the order of $\geq 1$ month) (25); therefore, the estimated positive correlations between FHB intensity and environment from longerlength time windows ( $\geq 30$ days) are directly applicable to any consideration of climate change or climatic patterns and subsequent disease development. Although the environment during critical time windows clearly affects FHB epidemics, grain yield, resulting toxin contamination of grain, and the relationship between FHB intensity and the environment are variable, and the disease responses are also strongly influenced by resistance of the cultivars grown, use of fungicides, and cultural practices such as rotation and type of tillage $(20,50)$. Cultivars with quantitative (partial) resistance are slowly being released and adopted by growers, although many factors influence whether a grower will use a less susceptible cultivar $(28,32)$. Moreover, growers may not be willing to use cultural practices that may reduce the intensity of this disease. Thus, the disease will likely continue to exhibit sporadic patterns over multiple years, based on the favorability (or lack of favorability) of environmental conditions. Knowledge of the relationship between FHB intensity and environment aids in predicting major epidemics and in making decisions on the use of fungicide for disease control.

\section{ACKNOWLEDGMENTS}

Salaries and research support were provided by state and federal funds to the Ohio Agricultural Research and Development Center. This investigation is based upon work supported, in part, by the United States Department of Agriculture (USDA) (agreement no. 59-0790-4-112). Further support was supplied by USDA Cooperative State Research, Education, and Extension Service Special Grant 2008-34493-19444. This is a cooperative project with the U.S. Wheat \& Barley Scab Initiative. Any opinions, findings, conclusions, or recommendations expressed in this publication are those of the authors and do not necessarily reflect the view of the USDA. We thank M. McMullen of North Dakota State University, E. De Wolf of Kansas State University, and G. Shaner of Purdue University for supplying data from their respective states for use in this analysis.

\section{LITERATURE CITED}

1. Anderson, A. L. 1948. The development of Gibberella zeae headblight of wheat. Phytopathology 38:595-611. 
2. Arseniuk, E., Foremska, E., Góral, T., and Chełkowski, J. 1999. Fusarium head blight reactions and accumulation of deoxynivalenol (DON) and some of its derivatives in kernels of wheat, triticale and rye. J. Phytopathol. 147:577-590.

3. Arthur, J. C. 1891. Wheat scab. Indiana Agric. Exp. Stn. Bull. 36:129132.

4. Atanasoff, D. 1920. Fusarium blight (scab) of wheat and other cereals. J. Agric. Res. 20:1-32.

5. Bai, G., and Shaner, G. 1994. Scab of wheat: Prospects for control. Plant Dis. 78:760-766.

6. Bai, G.-H., and Shaner, G. 1996. Variation in Fusarium graminearum and cultivar resistance to wheat scab. Plant Dis. 80:975-979.

7. Birzele, B., Meier, A., Hindorf, H., Krämer, J., and Dehne, H.-W. 2002. Epidemiology of Fusarium infection and deoxynivalenol content in winter wheat in the Rhineland, Germany. Eur. J. Plant Pathol. 108:667-673.

8. Calvero, S. B., Jr., Coakley, S. M., and Teng, P. S. 1996. Development of empirical forecasting models for rice blast based on weather factors. Plant Pathol. 45:667-678.

9. Christensen, J. J., Stakman, E. C., and Immer, F. R. 1929. Susceptibility of wheat varieties and hybrids to Fusarial head blight in Minnesota. Minn. Agric. Exp. Stn. Bull. 59.

10. Chuang, T. Y., and Jeger, M. J. 1987. Predicting the rate of development of Black Sigatoka (Mycosphaerella fijiensis var. difformis) disease in southern Taiwan. Phytopathology 77:1542-1547.

11. Coakley, S. M., and Line, R. F. 1982. Prediction of stripe rust epidemics on winter wheat using statistical models. (Abstr.) Phytopathology 72:1006.

12. Coakley, S. M., Line, R. F., and McDaniel, L. R. 1988. Predicting stripe rust severity on winter wheat using an improved method for analyzing meteorological and rust data. Phytopathology 78:543-550.

13. Coakley, S. M., McDaniel, L. R., and Shaner, G. 1985. Model for predicting severity of Septoria tritici blotch on winter wheat. Phytopathology 75:1245-1251.

14. Cowger, C., Patton-Özkurt, J., Brown-Guedira, G., and Perugini, L. 2009. Post-anthesis moisture increased Fusarium head blight and deoxynivalenol levels in North Carolina winter wheat. Phytopathology 99:320327.

15. Culler, M. D., Miller-Garvin, J., and Dill-Macky, R. 2007. Effect of extended irrigation and host resistance on deoxynivalenol accumulation in Fusarium-infected wheat. Plant Dis. 91:1464-1472.

16. Del Ponte, E. M., Fernandes, J. M. C., and Pavan, W. 2005. A risk infection simulation model for Fusarium head blight of wheat. Fitopatol. Brasil. 30:634-642.

17. De Wolf, E., Molineros, J., Madden, L., Lipps, P., Knight, P., and Miller, D. 2005. Future directions in the development and application of risk assessment models for Fusarium head blight. Page 117 in: Proc. 2005 Natl. Fusarium Head Blight Forum, Milwaukee, WI.

18. De Wolf, E. D., and Isard, S. A. 2007. Disease cycle approach to plant disease prediction. Annu. Rev. Phytopathol. 45:203-220.

19. De Wolf, E. D., Madden, L. V., and Lipps, P. E. 2003. Risk assessment models for wheat Fusarium head blight epidemics based on within-season weather data. Phytopathology 93:428-435.

20. Dill-Macky, R., and Jones, R. K. 2000. The effect of previous crop residues and tillage on Fusarium head blight of wheat. Plant Dis. 84:7176.

21. Dufault, N. S., De Wolf, E. D., Lipps, P. E., and Madden, L. V. 2006. Role of temperature and moisture in the production and maturation of Gibberella zeae perithecia. Plant Dis. 90:637-644.

22. Fernando, W. G. D., Paulitz, T. C., Seaman, W. L., Dutilleul, P., and Miller, J. D. 1997. Head blight gradients caused by Gibberella zeae from area sources of inoculum in wheat field plots. Phytopathology 87:414-421.

23. Francl, L. J., Madden, L. V., Rowe, R. C., and Riedel, R. M. 1990. Correlation of growing-season environmental variables and the effect of early dying on potato yield. Phytopathology 80:425-432.

24. Gilbert, J., Woods, S. M., and Kromer, U. 2008. Germination of ascospores of Gibberella zeae after exposure to various levels of relative humidity and temperature. Phytopathology 98:504-508.

25. Hansen, J. W., Challinor, A., Ines, A., Wheeler, T., and Moron, V. 2006. Translating climate forecasts into agricultural terms: Advances and challenges. Clim. Res. 33:27-41.

26. Hart, L. P., Pestka, J. J., and Liu, M. T. 1984. Effect of kernel development and wet periods on production of deoxynivalenol in wheat infected with Gibberella zeae. Phytopathology 74:1415-1418.

27. Hochberg, Y., and Rom, D. 1995. Extensions of multiple testing procedures based on Simes' test. J. Stat. Plann. Inference 48:141-152.

28. Hollingsworth, C. R., Motteberg, C. D., Wiersma, J. V., and Atkinson, L. M. 2008. Agronomic and economic responses of spring wheat to management of Fusarium head blight. Plant Dis. 92:1339-1348.

29. Hooker, D. C., Schaafsma, A. W., and Tamburic-Ilincic, L. 2002. Using weather variables pre- and post-heading to predict deoxynivalenol content in winter wheat. Plant Dis. 86:611-619.

30. Lipps, P. E., Madden, L. V., Mills, D. R., and Paul, P. A. 2005. Forecasting Fusarium head scab of wheat in Ohio in 2005 and summary of disease levels, 2002-2005. Ohio Agricultural Research and Development Center, Plant Pathology Department Series 128.

31. Lu, W. H., Chen, S. H., and Wang, Y. Z. 2001. Research of Fusarium Head Scab in China. Science Publisher, Beijing.

32. McMullen, M., Jones, R., and Gallenberg, D. 1997. Scab of wheat and barley: A re-emerging disease of devastating impact. Plant Dis. 81:13401348.

33. Moschini, R. C., and Fortugno, C. 1996. Predicting wheat head blight incidence using models based on meteorological factors in Pergamino, Argentina. Eur. J. Plant Pathol. 102:211-218.

34. Nganje, W. E., Bangsund, D. A., Leistritz, F. L., Wilson, W. W., and Tiapo, N. M. 2004. Regional economic impacts of Fusarium head blight in wheat and barley. Rev. Agric. Econ. 26:332-347.

35. Nita, M., De Wolf, E., Madden, L., Paul, P., Shaner, G., Adhikari, T., Ali, S., Stein, J., Osborn, L., and Wegulo, S. 2008. Use of mechanistic simulation models to predict disease intensity of Fusarium head blight and deoxynivalenol concentration. (Abstr.) Phytopathology 98:S113.

36. Parry, D. W., Jenkins, P., and McLeod, L. 1995. Fusarium ear blight (scab) in small grains cereals-a review. Plant Pathol. 44:207-238.

37. Paul, P. A., El-Allaf, S. M., Lipps, P. E., and Madden, L. V. 2004. Rain splash dispersal of Gibberella zeae within wheat canopies in Ohio. Phytopathology 94:1342-1349.

38. Paul, P. A., Lipps, P. E., De Wolf, E., Shaner, G., Buechley, G., Adhikari, T., Ali, S., Stein, J., Osborne, L., and Madden, L. V. 2007. A distributedlag analysis of the relationship between Gibberella zeae inoculum density on wheat spikes and weather variables. Phytopathology 97:1608-1624.

39. Paul, P. A., Lipps, P. E., and Madden, L. V. 2005. Relationship between visual estimates of Fusarium head blight intensity and deoxynivalenol accumulation in harvested wheat grain: A meta-analysis. Phytopathology 95:1225-1236

40. Paulitz, T. C. 1996. Diurnal release of ascospores by Gibberella zeae in inoculated wheat plots. Plant Dis. 88:724-730.

41. Pietravalle, S., Shaw, M. W., Parker, S. R., and van den Bosch, F. 2003. Modeling of relationships between weather and Septoria tritici epidemics on winter wheat: A critical approach. Phytopathology 93:1329-1339.

42. Prandini, A., Sigolo, S., Filippi, L., Battilani, P., and Piva, G. 2009. Review of predictive models for Fusarium head blight and related mycotoxin contamination in wheat. Food Chem. Toxicol. 47:927-931.

43. Proschan, M. A., and Waclawiw, M. A. 2000. Practical guidelines for multiplicity adjustment in clinical trials. Control. Clin. Trials 21:527-539.

44. Rossi, V., Giosuè, S., Pattori, E., Spanna, F., and Del Vecchio, A. 2003. A model estimating the risk of Fusarium head blight on wheat. OEPP/EPPO Bull. 33:421-425.

45. Rossi, V., Ravanetti, A., Pattori, E., and Giosuè, S. 2001. Influence of temperature and humidity on the infection of wheat spikes by some fungi causing Fusarium head blight. J. Plant Pathol. 83:189-198.

46. Rothman, K. J. 1990. No adjustments are needed for multiple comparisons. Epidemiology 1:43-46.

47. Rotter, B. A. 1996. Toxicology of deoxynivalenol (vomitoxin). J. Toxicol. Environ. Health 48:1-34.

48. Savitz, D. A., and Olshan, A. F. 1995. Multiple comparisons and related issues in the interpretation of epidemiologic data. Am. J. Epidemiol. 142:904-908.

49. Schaafsma, A. W., and Hooker, D. C. 2007. Climatic models to predict occurrence of Fusarium toxins in wheat and maize. Int. J. Food Microbiol. 119:116-125.

50. Schaafsma, A. W., Tamburic-Llincic, L., and Hooker, D. C. 2005. Effect of previous crop, tillage, field size, adjacent crop, and sampling direction on airborne propagules of Gibberella zeae/Fusarium graminearum, Fusarium head blight severity, and deoxynivalenol accumulation in winter wheat. Can. J. Plant Pathol. 27:217-224.

51. Schroeder, H. W., and Christensen, J. J. 1963. Factors affecting resistance of wheat to scab caused by Gibberella zeae. Phytopathology 53:831-838.

52. Sheskin, D. J. 2007. Spearman's Rank-Order Correlation Coefficient. Pages 1353-1370 in: Handbook of Parametric and Nonparametric Statistical Procedures, 4th ed. Chapman \& Hall/CRC, FL.

53. Simes, R. J. 1986. An improved Bonferroni procedure for multiple tests of significance. Biometrika 73:751-754.

54. Snijders, C. H. A. 1990. Genetic variation for resistance to Fusarium head blight in bread wheat. Euphytica 50:171-179.

55. Spearman, C. 1904. The proof and measurement of association between two things. Am. J. Psychol. 15:72-101.

56. Stevens, N. E. 1934. Stewart's disease in relation to winter temperatures. Plant Dis. Rep. 18:141-149.

57. Sutton, J. C. 1982. Epidemiology of wheat head blight and maize ear rot caused by Fusarium graminearum. Can. J. Plant Pathol. 4:195-209.

58. Te Beest, D. E., Paveley, N. D., Shaw, M. W., and van den Bosch, F. 2008. 
Disease-weather relationships for powdery mildew and yellow rust on winter wheat. Phytopathology 98:609-617.

59. Walker, S. L., Leath, S., Hagler, W. M., and Murphy, J. P. 2001. Variation among isolates of Fusarium graminearum associated with Fusarium head blight in North Carolina. Plant Dis. 85:404-410.

60. Westfall, P. H., Tobias, R. D., Rom, D., Wolfinger, R. D., and Hochberg, Y. 1999. Multiple Comparisons and Multiple Tests: Using the SAS System. SAS Institute Inc., Cary, NC.

61. Wilcoxson, R. D., Kommedahl, T., Ozmon, E. A., and Windels, C. E. 1988. Occurrence of Fusarium species in scabby wheat from Minnesota and their pathogenicity to wheat. Phytopathology 78:586-589.
62. Windels, C. E. 2000. Economic and social impacts of Fusarium head blight: Changing farms and rural communities in the Northern Great Plains. Phytopathology 90:17-21.

63. WMO. 1996. Page 501 in: Guide to Meteorological Instruments and Methods of Observation, 6th ed. WMO-No. 8, World Meteorological Organization.

64. Xu, X., and Nicholson, P. 2009. Community ecology of fungal pathogens causing wheat head blight. Annu. Rev. Phytopathol. 47:83-103.

65. Yue, S., Pilon, P., and Cavadias, G. 2002. Power of the Mann-Kendall and Spearman's rho tests for detecting monotonic trends in hydrological series. J. Hydrol. 259:254-271. 